\title{
A MICROMACHINED KNIFE GATE VALVE FOR HIGH-FLOW PRESSURE REGULATION APPLICATIONS
}

\author{
Wouter van der Wijngaart, Anthony S. Ridgeway, Göran Stemme \\ Microsystem Technology, Department of Signals, Sensors, and Systems, Royal Institute of Technology,
} SE-10044 Stockholm, Sweden.

\begin{abstract}
Cross-flow pressure regulating valve structures are attractive for high-flow pressure control applications due to the decreased actuation force required and the reduced device footprint area. A knife gate valve was fabricated, controlling a flow of $1.3 \mathrm{Nl} / \mathrm{min}$ at a supply pressure of 1.5 bar. The valve was microfabricated using deep reactive ion etching (DRIE) and silicon fusion bonding. The use of micromachined knife gate valves in pressure control systems enhances performance and cost savings can be realized.
\end{abstract}

\section{INTRODUCTION}

One area of industry that holds potential for the introduction of microsystems is pressure regulation and control. Pressure controllers (also $E / P$-converters or $1 / P$ converters where $E$ stands for electrical, $I$ for current and $P$ for pressure), are basic elements in a vast number of industrial applications. Their basic function is to convert an electrical control signal into a work pressure $P_{\text {work }}$. Figure 1 shows a typical converter and its performance characteristics. The structure has three pneumatic ports: one supply port, indicated with index supply, one work port, indicated with index work, and one vent port, indicated with the indices vent or atm (this port is in most applications coupled to atmospheric pressure).
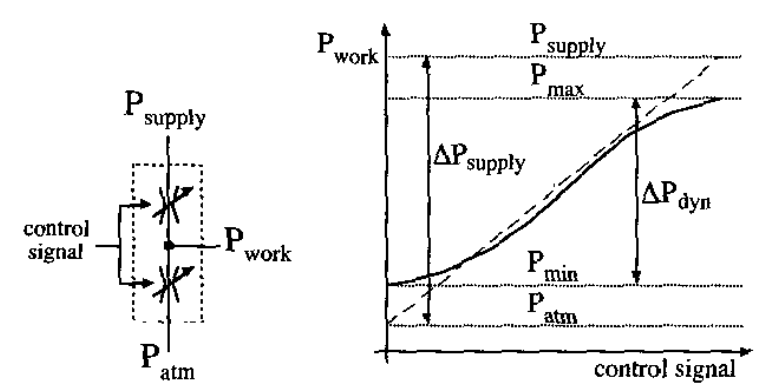

Figure 1. Functional representation of a pressure control element (left) and its pressure characteristics (right). The dashed line in the plot indicates the ideal behavior, while the solid line indicates a typical actual performance.

In the ideal case the valve would be able to control the work pressure over the entire range $\left(\Delta \mathrm{P}_{\text {supply }}\right)$ between the atmospheric pressure $\left(\mathrm{P}_{\mathrm{atm}}\right)$ and the high supply pressure $\left(\mathbf{P}_{\text {supply }}\right)$. In an actual case the valve controls a smaller dynamic range $\left(\Delta P_{\text {dyn }}\right)$, which is the difference between a maximum pressure $\left(P_{\max }\right)$, slightly below the supply pressure, and a minimum pressure $\left(\mathbf{P}_{\min }\right)$, slightly above the atmospheric pressure.

Pressure controllers would benefit from the cost advantages of microfabrication if performance can be maintained in terms of pressure and flow characteristics. Efforts have been made in the past to develop microvalves for pneumatic systems, however most cannot meet the demands of industrial use. Most previously reported microvalves are seat valves and utilize out-of-plane flow and actuation by means of a valve seat and boss [1-6]. The limited boss stroke-length severely limits their flow performance by the inherent restriction of the small flow ducts. Moreover, the static pneumatic force counteracts the valve actuation. To obtain a large flow rate and a high-pressure control performance with such valves the device footprint area must be increased accordingly. This decreases the device count per batch and thus increases manufacturing costs.

This paper introduces and proves a pressure control microvalve suitable for replacing large-scale valves. The novel device presented features an increased flow-pressure performance per device footprint area as compared to previously presented microvalves [1-7].

\section{THEORY AND DESIGN}

A knife gate microvalve (Figure 2) has been developed which circumvents the above performance drawbacks.

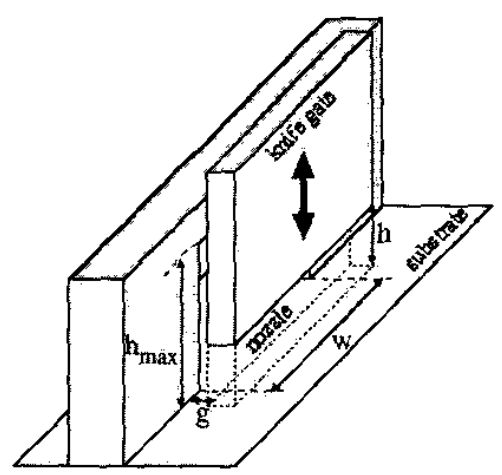

Figure 2. The knife gate valve principle.

The valve gate moves perpendicular to the flow and the static pneumatic force (hence the name cross-flow valve or $X$-Valve). The static pressure and valve actuation are not counteracting one another, thereby reducing the required actuator force and size. Moreover, the X-Valve features in-plane gas flow and out-of-plane gate 
displacement. Unlike all previously reported microvalves the nozzle area is perpendicular to the wafer plane; therefore the footprint area consumed by the device is independent from its pressure and flow performance. The $\mathrm{X}$-Valve thus allows control of larger flow and higher pressure with a more compact design.

The X-Valve requires spacing between the gate and the nozzle to avoid friction and therefore leaks in the closed state. However, in pressure controller applications this is of minor importance. Leakage influences the controller's static 'pneumatic energy loss and reduces the dynamic pressure range of the device

$\Delta P_{d y n}=P_{m a x}-P_{\min }<\Delta P_{\text {supply }}=P_{\text {supply }}-P_{\text {atm }} \quad$ (Figure 1).

For lower Mach numbers and for device dimensions of interest, frictional losses in the leak gap are negligible. This results from the low ratio of the gate-nozzle spacing ( $g$ ) over leak path length and the smoothness of the (micromachined) surface of the leak path [8]. If at high Mach numbers frictional losses do occur, they would further decrease the leakage. Both the main flow and leak flow can thus be modeled as isentropic flow in a sudden expansion, in which the mass-flow

$$
\dot{m} \propto A_{c s} P_{s u p p l y}\left(\frac{P_{a t m}}{P_{s u p p l y}}\right)^{1 / \gamma} \sqrt{\left(\frac{P_{s u p p l y}}{P_{a t m}}\right)^{1-1 / \gamma}-1}
$$

with $A_{c s}$ being the minimal cross-sectional area of the flow path and $\gamma$ the gas specific heat ratio $[8,9]$. The leak rate can then be quantified as

$$
\eta=\frac{\dot{m}_{\text {leak }}^{l}}{\dot{m}_{\text {max }}}=\frac{A_{c s_{-} \text {leak }}}{A_{c s_{-} \max }}=\frac{\left(2 h_{\text {max }}+w\right) \cdot g}{h_{\max } \cdot w}=\frac{g}{h_{\text {max }}}
$$

for $w>h_{\max }$, with $h_{\max }$ the nozzle height, $w$ the nozzle width, and the indices leak and max referring to the conditions and dimensions at the gate-nozzle spacing and the maximum nozzle opening, respectively.

For a pressure controller as illustrated in Figure 1 containing two identical control valves with leak rate $\eta$, $P_{\min }$ and $P_{\max }$ can be calculated using the mass flow continuity equation

$$
\dot{m}_{\text {supply }}=\dot{m}_{\text {work }}+\dot{m}_{a t m}=\dot{m}_{a t m}
$$

at zero work flow. $P_{\text {work }}=P_{\min }$ if the vent port is open and the supply port is closed, in which case $A_{c_{\text {s_supply }}}=$ $\eta \cdot A_{\text {cs } y e n,}$, respectively $P_{\text {work }}=P_{\max }$ if the vent port is closed and the supply port is open, in which case $A_{c s \text { vent }}=$ $\eta \cdot A_{c s_{s} \text { supply. }} . P_{\text {min }}$ and $P_{\text {max }}$ can thus be calculated as the respective solutions of the equations

$$
\begin{aligned}
& \left.\eta \cdot P_{\text {supply }} \frac{P_{\min }}{P_{\text {supply }}}\right)^{1 / \gamma} \sqrt{\left.\frac{P_{\text {supply }}}{P_{\min }}\right)^{1-1 / \gamma}-1} \\
& =P_{\min }\left(\frac{P_{a t m}}{P_{\min }}\right)^{1 / \gamma} \sqrt{\left(\frac{P_{\min }}{P_{a t m}}\right)^{1-1 / \gamma}-1}
\end{aligned}
$$

and

$$
\begin{aligned}
& P_{\text {supply }}\left(\frac{P_{\max }}{P_{\text {supply }}}\right)^{1 / \gamma} \sqrt{\left(\frac{P_{\text {supply }}}{P_{\max }}\right)^{l-1 / \gamma}-1} \\
& \left.=\eta \cdot P_{\max } \frac{P_{a t m}}{P_{\max }}\right)^{1 / \gamma} \sqrt{\left.\frac{P_{\max }}{P_{a t m}}\right)^{1-1 / \gamma}-1}
\end{aligned}
$$

Graphically solving these equations for 1 bar (relative) supply pressure shows that for a leak rate $\eta=20 \%, P_{\max }=$ 0.9815 bar and $P_{\min }=0.0376 \mathrm{bar}$, resulting in a pressure range $\frac{\Delta P_{d y n}}{\Delta P_{\text {supply }}}=94.4 \%$.

\section{FABRICATION}

A non-optimized demonstrator structure, requiring minimum processing, was fabricated using silicon bulk micromachining and silicon fusion bonding and is shown in Figure 3.
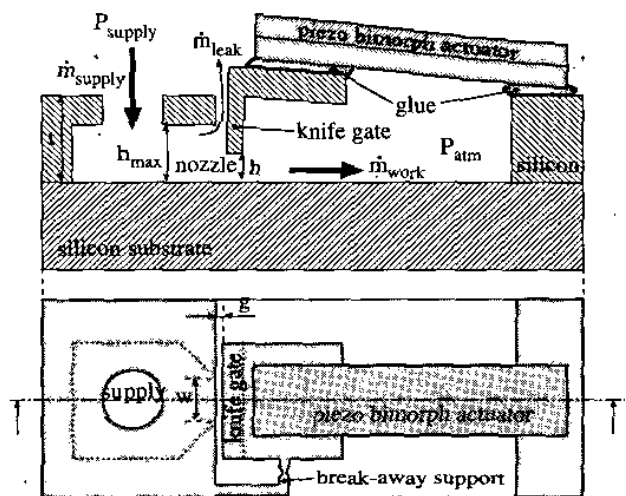

Figure 3. Simplified drawing of the demonstrator $X$ Valve structure.

Figure 4 shows the processing steps used to fabricate the structure. To start, a $200 \mu \mathrm{m}$ thick doubleside-polished silicon wafer is spin coated with resist and patterned. The front-side of the device is DRIE etched to a depth of $130 \mu \mathrm{m}$ (Figure $4 \mathrm{a}$ ). Next, thermal oxide $1 \mu \mathrm{m}$ thick is grown (Figure 4b). The resist is then removed using oxygen plasma. The backside is patterned and DRIE etched to a depth of $h_{\max }=70 \mu \mathrm{m}$ defining the maximum gate opening (Figure $4 \mathrm{c}, \mathrm{d}$ ). The resist is again stripped using oxygen plasma and the oxide is removed using a buffered HF solution releasing a fallout structure (Figure 4e). The $200 \mu \mathrm{m}$ machined wafer is silicon fusion bonded with a $500 \mu \mathrm{m}$ single-side-polished wafer (Figure 4f). After drilling an inlet opening, a fluid connector is attached as well as a piezoelectric bimorph actuator using a two-part adhesive epoxy. The structure, supporting the knife gate during manufacturing, is now removed by breaking (Figure $4 \mathrm{~g}$ ). Note that the use of fall-out structures and the opening of the fluid connector with a mechanical drill were chosen in this fabrication scheme to 
minimize the exposed silicon area during the first DRIE step and thus optimize the etch quality.

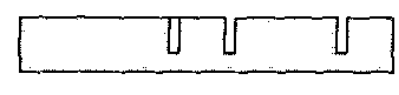

a. DRIE-ing.
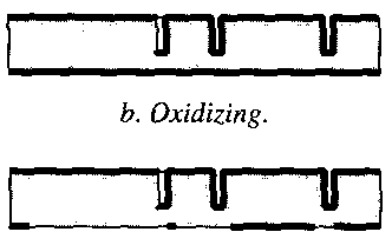

c. Backside patterning.

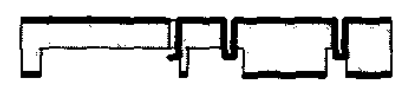

d. Backside DRIE-ing.
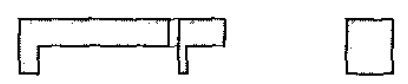

e. HF. etching.

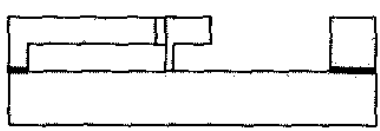

f. SFB, followed by an $H F$ release etching.

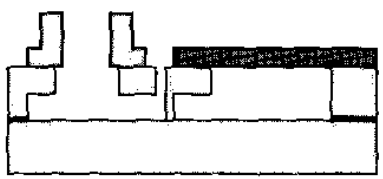

g. Mounting of the piezo acuator, tube connector and breaking of the support arms.

Figure 4. Simplified drawings, illustration the processing steps for the fabrication of the demonstrator $X$-Valve structure.

\section{EXPERIMENTAL RESULTS}

A demonstrator structure with dimensions $g=$ $10 \mu \mathrm{m}, h_{\max }=70 \mu \mathrm{m}$, and $w=2 \mathrm{~mm}$ (Figure 2) was fabricated and tested. Note that the $10 \mu \mathrm{m}$ gate-nozzle spacing did not hinder the movement of the gate.

The demonstrator structure was tested by measuring the flow rate through the device at varying supply pressure and gate opening height. The inlet of the structure was supplied with pressures of $0.2,0.5,1$, and $1.5 \mathrm{bar}$. At each of these inlet pressures the flow rate was measured for different gate opening heights. Figures 5 and 6 show the flow measurements of the demonstrator structure as functions of the valve gate opening and supply pressure, respectively.

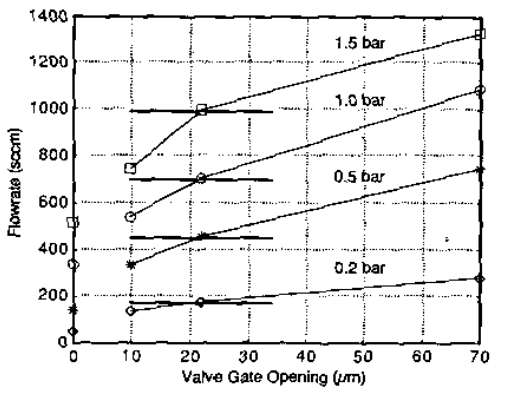

Figure 5. The measured valve flow rate $Q_{\text {supply }}$ versus the gate opening $h$ at different supply pressures $P_{\text {suppty }}$

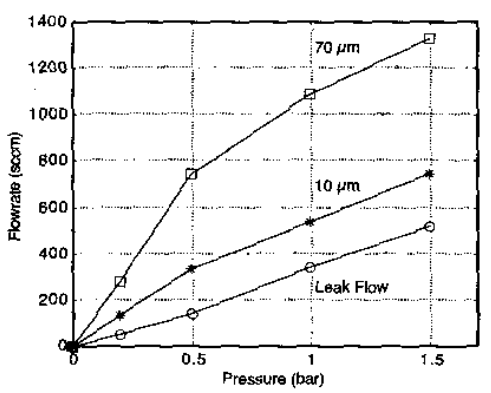

Figure 6. The measured valve flow rate $Q_{\text {supply }}$ versus the supply pressure $P_{\text {supply }}$ at different gate openings $h$.

During fabrication, some $10 \mu \mathrm{m}$ sized silicon structures, used for improved fabrication characteristics, detached and became fixed under the knife gate, which in turn would not allow the valve to fully close. These structures create a minimum gate opening of exactly 10 $\mu \mathrm{m}$ when the knife gate is closed and attribute to the according flow measurement, shown in Figures 5 and 6. The zero gate opening flow, i.e. the pure leak flow, was measured using an identical device with a non-adjustable gate, fabricated for the purpose of leak flow testing. In the other measurements, the gate opening height was adjusted by applying voltage to the piezoelectric bimorph element. The gate opening was determined visually with a microscope. The uncertainty in the gate opening measurements gives rise to the large errors, indicated with bars in Figure 5 for the flow measurement at $22 \mu \mathrm{m}$ gate opening.

The leak flow through the valve at 0.5 bar was approximately $0.15 \mathrm{Nl} / \mathrm{min}$, which is about $19.5 \%$ of the measured maximum flow. This valve performance makes the structure a viable candidate for pressure controller applications. Moreover, the pressure-flow performance of the demonstrator valve, $1.3 \mathrm{Nl} / \mathrm{min}$ at 1.5 bar supply pressure, is a factor of two better than previously reported values for microvalves.

\section{COMPLETE MICROFABRICATED IP-CONVERTER}

With the proven performance of the X-Valve concept a complete microfabricated IP-converter design is 
proposed that combines two X-Valves in a fully packaged and operable device. Figure 7 gives the details of the makeup of the micromachined core of the device and its basic functions.
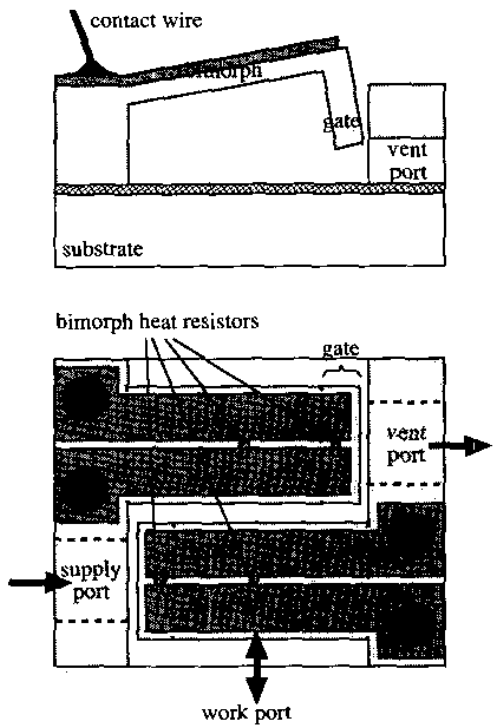

Figure 7. Schematic cross-sectional and top view of a micro pressure controller with two X-Valves (not to scale).

The pneumatic connectors will be integrated in the sides of the chip package. Actuation for the valves is provided by cantilevered thermal bimorphs. One X-Valve provides flow regulation at the supply port while a second $\mathrm{X}$-Valve provides flow regulation at the vent port. A third port is used for the work flow $\left(\mathrm{Q}_{\text {work }}\right)$. With the supply port closed and vent port open, the work area is evacuated. With the supply fully open and the vent closed the maximum work pressure is generated. The two $\mathrm{X}$ $V$ alves can be actuated either together or independently to achieve the work flow required.

\section{CONCLUSIONS AND FUTURE WORK}

We have presented a novel microvalve concept for pressure control applications. The design is the key element in a truly miniaturized micromachined highperformance pneumatic control element. A demonstrator structure was fabricated using DRIE and silicon fusion bonding. The demonstrator structure is actuated with a glued piezoelectric bimorph. The device was successfully tested and the flow-pressure and flow-gate opening performance were measured. The valve flow can be controlled gradually through the gate position. The pressure-flow performance of the demonstrator valve presented is a factor of two better than previously reported values for microvalves. Future work focuses on the fabrication of a complete micromachined pressure controller with integrated thermoelectric bimorph actuators.

\section{ACKNOWLEDGEMENTS}

The authors would like to thank Pondus Instruments AB, Stockholm, Sweden for sponsoring this research.

\section{REFERENCES}

[1] M. Huff, J. Gilbert, and M. Schmidt, "Flow characteristics of a pressure balanced microvalve," Proc. $7^{\text {th }}$ International Conference on Solid State Actuators (Transducers), Yokohama, Japan, June, 1993, pp. 98-101.

[2] H. Jerman, "Electrically-activated normally closed diaphragm valves," Journal of Micromechanics and Microengineering, vol. 4, pp. 210-216, 1994.

[3] S. Messner, M. Muller,'V. Burger, J. Schaible, H. Sandmaier, and R. Zengerle, "A normally-closed, bimetallically actuated 3-way microvalve for pneumatic applications," Proc. $11^{\text {th }}$ International Workshop on Micro Mechanical Systems, Heidelberg, 1998, pp. 159-164.

[4] P. W. Barth, C.C. Beatty, L.A. Field, J.W. Baker, and G.B. Gordon, "A robust normally closed silicon microvalve'," Technical Digest of the Solid-State Sensor and Actuator Workshop, Hilton Head, SC, USA, 1994, pp. 248-250.

[5] P.W. Barth, "Silicon microvalves for gas flow control," Proc. $8^{\text {th }}$ International Conference on Solid-State Sensors and Actuators and Eurosensors $I X$, Stockholm, Sweden, 1995, vol. 2, pp. 276-279.

[6] Mark J. Zdeblick, R. Anderson, J. Jankowski, B. Kline-Schoder, L. Christel, R. Miles, and W. Weber, "Thermopneumatically actuated microvalves and integrated electro-fluidic circuits," in Technical Digest of the Solid-State Sensor and Actuator Workshop, Hilton Head, South Carolina, USA, 1994, pp. 251-255.

[7] Kirt. R. Williams, N. Maluf, E. Fuller, R. Barron, D. Jaeggi, B. van Drieënhuizen, "A silicon microvalve for the proportional control of fluids," in Proc. $10^{\text {th }}$ International Conference on Solid-State Actuators (Transducers '99), Sendai, Japan, June, 1999, pp. 1804-1807.

[8] Frank M. White, Fluid mechanics. New York, NY: McGraw-Hill, $4^{\text {th }}$ edition, 1999.

[9] A. K. Henning, "A compact, pressure- and structurebased gas flow model for microvalves." In Proceedings, Materials and Device Characterization in Micromachining, International Society for Optical Engineering, Bellingham, WA, 2000; Y. Vladimirsky and P. J. Coane, eds., volume 4175. 